\title{
CRIAÇÃO E PROPOSIÇÕES PARA A ARTICULAÇÃO VIDEOGRÁFICA: FUNDAMENTOS PARA A PRODUÇÃO E ANÁLISE DE CONTEÚDO AUDIOVISUAL EDITÁVEL
}

\author{
CREATION AND PROPOSALS FOR VIDEO LINKAGE: GROUNDS FOR PRODUCTION AND ANALYSIS \\ OF EDITABLE AUDIOVISUAL CONTENT
}

\author{
CESTARI, Guilherme Henrique de Oliveira; Mestrando \\ Universidade Estadual de Londrina \\ gui_cestari@hotmail.com
}

\begin{abstract}
RESUMO
O Video/Visual Jockey (VJ) manipula em tempo real estímulos luminosos e audiovisuais para dar origem a uma apresentação performática, híbrida e tecnológica, por vezes, com aspecto catártico e extático. $O$ faz em museus, festas, apresentações teatrais, na internet, na televisão etc. $O$ presente artigo sintetiza os resultados da primeira etapa de uma pesquisa em andamento, considera discurso e linguagem do VJ e da videoarte e observa pressupostos empíricos para propor um modelo de criação de conteúdo para VJs. Este modelo, assim como a apresentação do VJ, não se mostra como estrutura rígida, mas foi concebido para descrever e orientar de maneira articulada a criação videográfica experimental. $O$ modelo compreende três momentos, especificados textual e imageticamente no decorrer do trabalho: concepção, planejamento e implementação.
\end{abstract}

Palavras chave: Vídeo Jóquei; Modelo; VJing.

\begin{abstract}
The Video / Visual Jockey (VJ) handles in realtime audiovisual and light stimulations to create a hybrid, technologic and, sometimes, cathartic and ecstatic performative presentation. The VJ's work appears in museums, festivals, theater plays, on the internet, television etc. This paper summarizes the results of the first stage of an ongoing research; considers video art and VJ's possible speeches and languages to propose a model of content creation for VJs; this model is not as rigid structure, it's designed to describe and articulately guide videographic experimental setting. The model covers three stages: design, planning and implementation.
\end{abstract}

Keywords: Video Jockey; Model; VJing.

A fragmentação do discurso e das experiências é característica das poéticas contemporâneas. Tem-se por VJing o processo que inclui produção, projeção, edição e sincronização de interferências visuais, luminosas e sonoras em tempo real, de maneira a originar uma atuação performática. É uma prática contemporânea que tem o potencial de suprir necessidades informacionais de determinado público. $O$ discurso da performance audiovisual valoriza, por meio da profusão luminosa e da articulação de diferentes estímulos, a ludicidade e o uso de metáforas sinestésicas. O resultado tende a uma experiência de "confusão" sensorial única, individual e, ao mesmo tempo, com certo grau de cumplicidade e compartilhamento entre os participantes.

$\mathrm{O}$ indivíduo que se apresenta nos moldes citados tem o nome de "VJ" (Video ou Visual 
Criação e proposições para a articulação videográfica: fundamentos... conteúdo audiovisual editável

Jokey, em paralelo ao DJ, ou Disc Jokey). As áreas do conhecimento com que lida vão desde a Usabilidade e Ergonomia à Semiótica Aplicada, passando pela llustração, Antropologia, Estética e mesmo História da Arte. Apesar de possuir origens e influências na modernidade, tornandose possível com o desenvolvimento técnico e com o conhecimento pragmático, o VJing é fruto de dissovências, atua de forma não-pontual, espalhada, ambígua, multilateral e simultânea, o que o caracteriza como estrutura rizomática, em forma de constelação, sem nódulos ou núcleos centrais, duros ou fixos. A imagem do VJ emana de um trabalho multidisciplinar, criativo e articulável que transpassa - polui, infiltra-se em - corporeidades convencionais; a colagem e referenciação de outros estilos tende a subverter paradigmas cotidianos em prol de releituras assimétricas, de movimentos exóticos, de direções e condutas oblíquas, incertas. $\mathrm{O} \mathrm{VJ}$ assume e recombina signos e valores de forma relativamente caótica e pode contribuir para a formação de uma sociedade em que sejam crescentemente empreendidos usos críticos, reflexivos e criativos da tecnologia em comunicação. Diante dos fáceis acesso e produção de conteúdo em vídeo, animação, desenho ou fotografia, além da popularização de iniciativas relacionadas à dança e à música, como contribuir para a divulgação e o aprofundamento da prática e da reflexão sobre a condição desta atividade?

Apesar da pesquisa teórica desenvolvida (CESTARI, 2011), este texto prioriza resultados. Atividade, modelos de linguagem e nomenclaturas associadas ao VJ normalmente não são reconhecidas ou diferenciadas pela maioria daqueles que usufruem de seu trabalho; sem identificação, VJ corre o risco de ter seu esforço reduzido a mero momento efêmero de entretenimento. A partir disto, delimitou-se o foco do trabalho: articular conhecimentos sobre o VJ, de maneira a colaborar para que este seja valorizado de forma prática (aplicando os conhecimentos para a construção de uma performance audiovisual) e teórica (refletindo sobre suas funções e lugares sociais e acerca dos signos por ele articulados).

Para executar sua apresentação performática e propor novas leituras, o VJ necessita de um acervo audiovisual. Podem fazer parte deste conjunto: imagens estáticas (fotografias ou ilustrações), vídeos retirados de programas televisivos, cinema ou internet, filmagens caseiras, animações geradas ao vivo, por câmeras portáteis ou por algoritmos computacionais, entre outros. Estes exemplos devem ser adaptados para a linguagem do VJ, uma vez que foram destituídos de suas mídias/suportes primeiros. Há, ainda, um tipo de conteúdo prévio que é produzido especialmente para a apresentação do VJ: o VJ loop: pequenos vídeos, que variam, normalmente, entre dois e vinte segundos de duração e, no decorrer da apresentação, são rearranjados de maneira a significar de forma conjunta e, assim, experimentar num contexto de constante construção e mutação. Este trabalho se dedicará à proposição de um modelo para a produção de loops; será criada uma estrutura que oriente e auxilie o VJ na relação com seu público e com a sociedade. Desta forma, pretende-se contribuir para a construção da cena do VJing e para a popularização da atividade.

\section{FUNDAMENTOS E ABORDAGENS METODOLÓGICAS}

A performance do VJ guarda certo potencial emocional e mobilizador, ao lidarem com linguagens em trânsito, tais imagens escapam a totalidades fechadas e autossuficientes. Concepções clássicas de "sujeito" e "autoria" são subvertidas pelo compartilhamento contínuo; experimentalismo, emotividade e ludicidade produzem sintaxes inusitadas. Espaço e tempo ficcionais permeiam o ambiente tecnológico, carnavalesco e extático. A materialidade convencional é descontruída e repensada ao defrontar-se com o signo luminoso que se projeta a partir de molduras telemáticas. A interferência do VJ mostra-se provocadora, ambígua e poliforme, os estímulos surgem de todos os lados num ode à sinestesia. A reapropriação 
degenera, singulariza, diferencia, recupera e explora as potencialidades de um conteúdo. 0 olhar encontra-se diante de uma multidão panorâmica de imagens e informações. O VJing constitui um fazer tipicamente metropolitano, forma-se de percursos incertos, (des)encontros nodais, alternativas inovadoras, engenharias não pragmáticas, maquinações vertiginosas, suspensões entrópicas. Apesar do gradual reconhecimento, o VJing não pode se desvincular totalmente da atuação marginal, alternativa, underground, daí procedem correlações ousadas, mesmo grotescas ou monstruosas, necessárias ao movimento não definitivo da cena e da atividade.

Foram desenvolvidas duas abordagens metodológicas a fim de dar origem ao modelo de produção de conteúdo para VJs. A primeira delas define-se na análise de uma apresentação da dupla de Disc Jockeys intitulada The Chemical Brothers. Operou-se uma visão estética e simbólica dos trabalhos do grupo sob um viés histórico, procurando identificar quais as abordagens dos DJs em relação a seu público e que usos fazem das imagens em suas apresentações. Entre os conhecimentos utilizados para dar respaldo às análises estão os atribuídos a autores como: Borges (2006), Machado (2007), Moran (2005, 2010), Munari (2004), Penteado (2006), Santaella (2005) e Santaella e Nöth (2008).

A segunda abordagem metodológica diz respeito a entrevistas realizadas com VJs que possuem diferentes abordagens com seus respectivos públicos. VJ Márcio tem uma atuação cujo impacto é restrito à cidade de Londrina e região. Faz apresentações em eventos sociais, como festas de aniversário e casamento. VJ Spetto é referência internacional e pioneiro no VJing no Brasil, começou a trabalhar com vídeo no início da década de 1990 e apresenta-se em grandes eventos. As conversas com ambos contribuíram para uma noção mais palpável da situação do VJ brasileiro, orientando a elaboração do modelo de criação de conteúdo.

\section{Criação de loops para apresentação performática}

Ao dizermos "modelo", já estamos implicando uma linha de discurso e uma decisão metodológica. [...] só nos referimos a um modelo na medida em que este possa ser manobrado: é um processo artesanal, operatório. Elabora-se um modelo para indicar uma forma comum a diversos fenômenos. (ECO, 1997, p. 26)

Identificar, descrever e analisar a criação de performances e conhecimentos prescinde parcialidade e subjetividade. Um modelo de criação é tradução de determinadas percepções e não opera de modo totalitário. O modelo não é dado, é construído, e se reporta a contextos sociais, políticos, econômicos, científicos, artísticos e culturais mais abrangentes. A concepção de um modelo pode orientar VJs iniciantes ou acrescentar ao trabalho dos veteranos. As relações estabelecidas e evidenciadas por este estudo não são imposições, mas sugestões. É conveniente que cada usuário leia os esquemas à sua maneira, sentindo-se livre para adaptálos às suas eventuais necessidades, conforme sua experiência com o Vjing. O esquema de estruturação informacional foi concebido tendo em vista dois tipos de aplicação: descritivoanalítica (ou seja, como recurso para uma eventual engenharia-reversa de uma apresentação audiovisual performática e/ou de loops nela utilizados) ou criativa e construtiva (sendo empregado para gerar novos conteúdos). É importante que uma estrutura de produção para VJs não leve em conta apenas estímulos visuais, mas congregue outros tipos de conteúdo e mídia sensoriais, como, por exemplo, áudio, gestualidade, iluminação, arquitetura etc. Eventuais "restrições" ao universo da visualidade, resultado de vícios no processo criativo, podem tornar as experiências menos enriquecedoras tanto para o público quanto para o Video Jockey. 0 
modelo de produção de loops possui três momentos principais: Conceituação, Planejamento e Implementação. Convém que o modelo não seja visto como uma estrutura linear, mas como um ciclo que se renova a cada aplicação.

\section{Conceituação}

Escolha e teorização tanto das mensagens a serem publicizadas quanto dos meios e indivíduos envolvidos na comunicação embasarão toda a atividade criativa. Daí a importância da boa conceituação para a fluência de uma apresentação performática. A base para a produção e classificação de apresentações e loops utilizados por VJs é triádica e pode ser traduzida em três perguntas acerca do conteúdo a ser concebido: "O que vou falar?", "Como vou falar?" e "Para quem vou falar?" (Cf. Figura 1).

Quando o usuário do modelo se pergunta "O quê?", é levado a pensar sobre a seleção de possíveis temas a serem abordados. De acordo com a entrevista concedida por Spetto, sendo o VJ "um contador de histórias", ele precisa ter algo para contar, um assunto, uma mensagem a ser transmitida. Assumindo a parcialidade inerente à comunicação, é importante que o VJ, projetado na criação artística, delineie sua poética e seu discurso ao assunto abordado, definindo a linguagem conceitual da performance ou do loop a ser produzido.

Com a mensagem estabelecida e clara, o VJ se pergunta "Como vou levar a informação ao público?". Este questionamento diz respeito aos meios utilizados para atingir público e sociedade: que forma(s) a(s) mensagem(s) irá(ão) tomar? Sob quais estruturas ela(s) irá(ão) ser levada(s) aos outros? Quais serão os equipamentos e recursos que permitirão a publicação e a ambientação das informações? Considerar-se-ão potenciais abordagens e modalidades de atuação, representação e performance. Por meio de quais sentidos a mensagem será apreendida? Por dizer respeito a meios de vinculação informacional, a pergunta "Como?" tem relações mais estreitas com o papel de comunicador social representado pelo VJ.

O VJ é também convidado a refletir "Para quem os meios irão levar a informação?". Considerando os receptores no processo comunicacional, é importante procurar conhecer a fundo o público e seus hábitos, costumes, rituais, crenças, preconceitos, expectativas e pretensões. Neste sub-tópico da construção conceitual o VJ é levado, sempre que possível, a procurar inspirações fora de seu universo particular e técnico, para assim conhecer as atividades sociais e culturais de seu público. Deste modo, curiosamente, o Visual Jockey imerge em espaços e situações buscando entender e absorver os olhares e os pensamentos daqueles que, supostamente, irão ocupar o espaço de sua apresentação. Ao preocupar-se com seu público, o VJ age como antropólogo visual, que traduz, em maior ou menor grau, as necessidades informacionais daqueles que o prestigiam. Por atender demandas sociais, tanto individuais quanto coletivas, o papel do VJ pode ser relacionado com o do designer, que problematiza e ressignifica matérias-primas para suprir carências.

Compreendido o eixo "O que - como - para quem" e respondidas as perguntas, há de se entender as relações entre as instâncias. Sugerir-se-ão possíveis estímulos que podem orientar o raciocínio em cada instância acima descrita: os inputs. Importantes para que as perguntas formuladas anteriormente sejam respondidas, os inputs, ou "entradas", são dados, informações e conhecimentos com as mais variadas origens e fontes. Responsáveis por estimular reflexões e discussões, os inputs fundamentam a atuação de cada uma das três instâncias da criação abstrata e conceitual.

Quando o usuário do modelo se pergunta "O que vou falar?", dando respaldo a uma postura de criação artística, procura informações em seu próprio repertório mental. Estas informações serão determinantes na constituição de um tema ou assunto e, posteriormente, de 
uma mensagem. Os principais inputs da instância artística da criação conceitual são lembranças, vivências, opiniões, pensamentos, sentimentos, emoções: tudo o que foi aprendido e se passa na mente do criador. Estes inputs têm natureza empírica e, por vezes, lúdica.

Ao se questionar "Como vou falar?" o VJ reporta-se a saberes de natureza mais técnica, uma vez que precisa conhecer os meios utilizados tanto em seu espaço de apresentação quanto em outros sistemas comunicacionais (como televisão, rádio, telefonia móvel e internet), se eventualmente desejar se apropriar destes. A pergunta então passa a ser: "Que estruturas eu utilizarei para materializar a mensagem que quero transmitir?". Para respondê-la, o VJ precisa conhecer sobre as tecnologias disponíveis, ou, quem sabe, desenvolver novas soluções que atendam às suas necessidades. Estes conhecimentos acerca dos meios de comunicação caracterizam o input relacionado ao VJ no papel de comunicador social.

"Para quem minha mensagem será destinada?" é pergunta que traduz a instância antropológica do VJ. Por meio desta, o usuário do modelo há de buscar informações relativas ao público visado e suas especificidades. Ideias que o permitam entender o mundo sob o olhar do outro: pesquisas de opinião e satisfação, cerimoniais ritualísticos, além de hábitos e costumes de jovens tribos urbanas, por exemplo. A pesquisa que diz respeito ao ambiente do público para o qual se apresentará o VJ é considerada input para a satisfação das necessidades dos eventuais ocupantes.

As instâncias de concepção abstrata operam de modo complementar. Porém, encontram-se, ainda, forças limitantes causadas pelas relações entre os três planos de abstração conceitual: as resistências e ressalvas na produção. A compreensão dos vetores de restrição permite que o usuário do modelo saiba lidar melhor com reações negativas do público e imprevistos de ordem técnica, operacional e estrutural. Apesar de permeada pelo improviso, pode haver imprevistos na apresentação. $O$ desrespeito a estas limitações pode causar consequências e sanções das mais diversas ordens: não aceitação da mensagem por parte do público, preconceito, violência verbal e física etc.

Admitindo que os constituintes do eixo "O que - como - para quem" se relacionam entre si, propõe-se uma triangulação entre as três instâncias com o intuito de verificar quais as possíveis relações entre elas. Encontram-se três tipos de relação: "O que - para quem", "Como - para quem" e "O que - como", cada qual com suas especificidades (Cf. Figura 1).

O cruzamento entre os inputs e objetivos das instâncias "O quê?" e "Para quem?" evidencia ressalvas de ordem social, cultural e abstrata. A escolha da mensagem a ser vinculada deve obedecer a critérios de aceitabilidade do público. Portanto, é importante voltar atenções para o modo de abordar determinados temas e símbolos em diferentes culturas.

As ressalvas a respeito das relações "Como - para quem" são, em sua maioria, de ordem sensorial, técnica e material. Os participantes da performance tem que estar em condições de apreender os estímulos articulados. Conforme Pignatari (1970), se há uma interferência no meio ou inerente ao(s) indivíduo(s), a mensagem não é apreendida como deveria, existe perda de informação.

As resistências "O que - como" acontecem nos planos operacional e de leitura/tradução linguística e informacional. O VJ deve assegurar-se que seus equipamentos permitam que a mensagem seja transmitida, atendendo às suas intencionalidades iniciais. As máquinas e os aparelhos são programados para servir ao Video Jockey transmitindo a mensagem satisfatoriamente. A mensagem não pode ser alterada pelo maquinário, a não ser que seja do feitio do VJ permiti-lo.

Após a exposição e exemplificação das relações entre as três instâncias de abstração, encerra-se o plano conceitual em direção ao planejamento, fase na qual os conceitos fundados e fundamentados na primeira fase tomarão forma. 


\section{Planejamento}

O planejamento visa amadurecer as abstrações oriundas na primeira parte do modelo. Para que sejam dotadas de originalidade e inovação, aconselha-se a busca por similares, a produção de rascunhos e esboços e, finalmente, a estruturação de um storyboard, caso necessário (Cf. Figura 2). A busca contínua por novas fontes e modelos de inspiração contribui para que o Visual Jockey se mantenha atualizado a respeito de tendências e comportamentos inovadores nas áreas do VJing e da teoria e prática ligadas à Comunicação Social e Visual. Utilizar-se-ão as mais diversas ferramentas para a pesquisa de similares: livros, revistas, jornais, artigos científicos, fotografias, documentários, conteúdos oriundos de blogs, portais digitais de notícia, bancos de imagem, conversas informais etc.

O primeiro momento da busca de obras que dialoguem com as diretrizes estipuladas consiste em congregar a maior quantidade e variedade de conteúdo possível. Com as referências coletadas em mãos, parte-se para uma segunda abordagem: a "filtragem" das informações. Lançando um olhar crítico sobre as obras coletadas, é importante que o VJ delimite os autores, trabalhos e ideias que serão de real importância para a construção de seu próprio conteúdo.

Com referências delineadas, sugere-se ao VJ que esboce visualmente a atuação do loop e/ou da apresentação a serem concebidos. A elaboração de rascunhos contribui para que o VJ vislumbre suas ideias com maior facilidade. Analisar diferentes combinações e possibilidades oferecidas pelos constituintes da apresentação permite que sejam feitos aprimoramentos no que se refere, principalmente, à organização espacial do ambiente destinado à performance. Aconselha-se a produção de traduções visuais sob diversos critérios e óticas de atuação, partindo do geral para o específico. Não há uma quantidade exata de rascunhos e estudos a serem realizados, os números podem variar de acordo com diversos fatores, tais como: familiaridade do VJ com determinado tipo de público, possíveis equipamentos e estruturas a serem utilizados, tempo hábil disponível até a finalização do trabalho etc.

Para a concepção de um loop ou apresentação audiovisual performática, apesar dos fatores que influenciam a quantidade, recomenda-se que, no mínimo, duas traduções visuais sejam produzidas. Correções estratégicas aliadas à divergência conceitual aplicada nos primeiros rascunhos contribuem para um equilíbrio entre ideal e realizável para a apresentação. Após os exercícios de simulação conceitual, estrutural e espacial, aconselha-se que o próximo passo seja o desenvolvimento de uma estrutura visual que oriente a produção. Um documento que possua descrições técnicas de todas as mídias utilizadas permite que o VJ explore a sintonia e o sincronismo entre os estímulos.

É interessante que no storyboard haja um equilíbrio entre imagem e texto. Operando de modo complementar, ambos possuem o objetivo de detalhar, de forma clara e legível, a apresentação ou o loop a ser desenvolvido. No modelo de produção concebido, o storyboard não tem o objetivo de cercear a atividade criativa, e sim de incentivar a exploração de novos recursos e linguagens. Evitando o puro empirismo, acredita-se que o planejamento e a constante revisão de conceitos são igualmente importantes para a adoção de posturas continuamente inovadoras e impactantes.

\section{Implementação}

Tendo utilizado imagem e texto para congregar todas as mídias e naturezas sensoriais a serem utilizadas durante a apresentação em documentos claros e concisos, o VJ estará apto a implementar as ações previstas no planejamento. Menos conceitual e mais prática, esta ocasião não prevê apenas a produção, mas possíveis ajustes no produto final para que estes 
CESTARI, Guilherme Henrique de Oliveira

sirvam de estímulo e inspiração para novos trabalhos (Cf. Figura 3). O tópico compreende as seguintes ações:

Execução: inclui todos os processos técnicos necessários, contratação de modelos e estúdios, filmagem, animação, gravação de áudio, busca por trechos de outras produções e o que for preciso para ter acesso aos conteúdos desejados.

Finalização: com todos os arquivos necessários em mãos, parte-se para a montagem e sincronização dos mesmos. É ao final deste estágio que o loop ficará pronto. Tendo em vista fins práticos ou poéticos e conceituais, cada plataforma e recurso utilizado possuem vantagens e desvantagens, cabendo ao usuário selecionar a mais conveniente para seu trabalho.

Arquivamento: VJs normalmente possuem vastas bibliotecas de conteúdo, seja ele autoral ou não. Estes sistemas de organização de dados terão sua eficácia colocada à prova no momento da apresentação, em que o improviso demanda que arquivos específicos sejam encontrados rapidamente e inseridos no lugar exato e no tempo previsto. Para catalogar o loop produzido, recomenda-se ao VJ que se reporte a todo o processo de criação, principalmente à conceituação. Atribuir palavras-chave baseadas na mensagem, nos meios e nos públicos visados, torna mais fácil a busca por determinado arquivo.

Apresentação: cada apresentação é única, cada espaço é único, cada público é único. Dificilmente existirá um show idêntico ao outro, por mais que os ambientes, performances e participantes se pareçam. É importante que o VJ, ao conhecer o lugar destinado à sua performance, tenha consciência de seus planejamentos, mas seja maduro o suficiente para se moldar às estruturas disponíveis. A improvisação, para o VJ, começa antes do show.

Feedback: Iniciada a performance, e mesmo depois de sua finalização, o VJ há de estreitar as relações com seu público, verificando as respostas para os estímulos que operou. Este retorno por parte dos participantes permite que o Visual Jockey analise a apreensão e o impacto que as mensagens articuladas tiveram sobre os ocupantes daquele espaço e sobre a sociedade em geral.

Melhoramento e ajustes: é importante que o VJ se utilize do mapeamento das respostas concedidas pelo público para eventualmente adequar os loops produzidos, além de dar origem a novas produções. Por isso, a cena do VJing pode ser vista como uma estrutura colaborativa, sempre em processo de (re)construção por buscar tendências inovadoras e criativas.

As correlações conjecturadas no modelo podem ser mais bem assimiladas com a observação de diagramas infográficos. A adoção do pressuposto empírico, em que se admite o aperfeiçoamento de uma atividade conforme vivências e experiências, permite considerar o processo como uma espécie de espiral cíclica (Figura 4). Por meio da retroalimentação, o resultado final respalda novas criações e articulações discursivas e poéticas. A rede de signos é generativa, a retroalimentação não representa repetição, mas constante revisão visando à inovação. Há expansão de repertório e de consciência no decorrer do processo. A terceira apresentação contém, ainda que implicitamente, a segunda, que, por sua vez, pressupõe a primeira. Relações sígnicas não operam silogística ou cumulativamente; memória, arquivamento e lembrança constituem complexos mecanismos emocionais de instrumentalização da realidade, que, acessada por meio da experiência, é formalizada pelo pensamento de modo a originar conhecimento. 


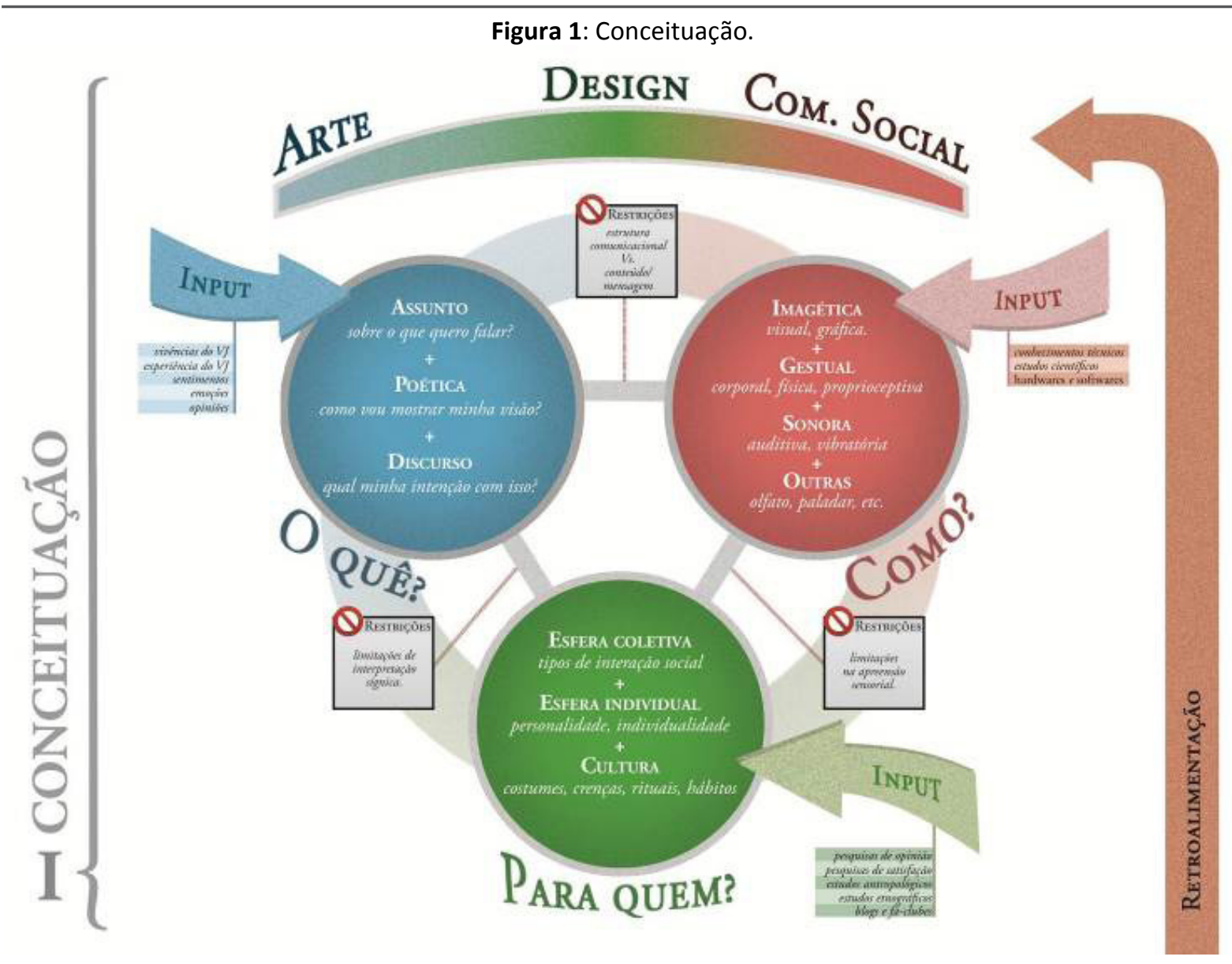

Figura 2: Planejamento.
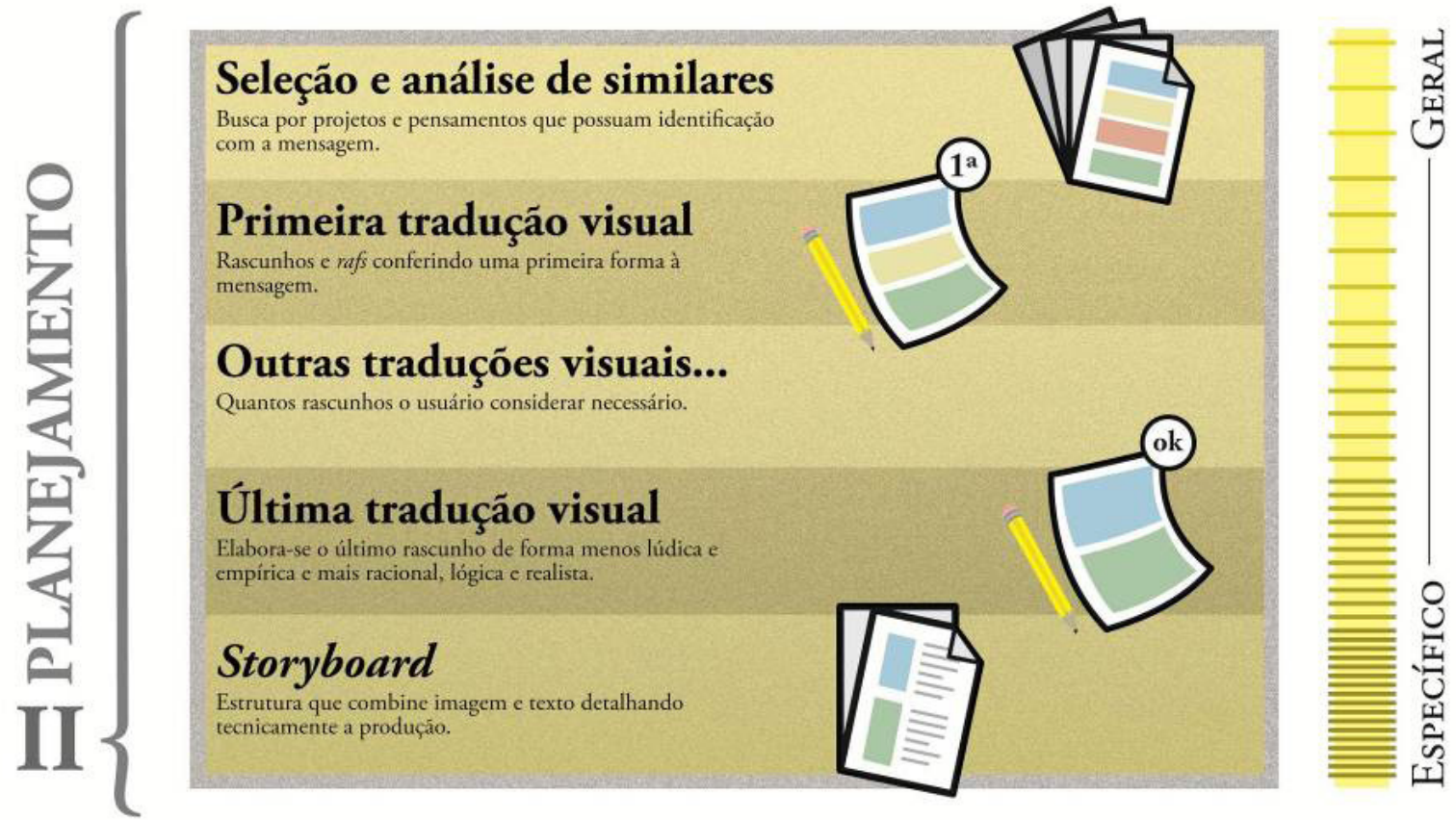
Figura 3: Implementação.
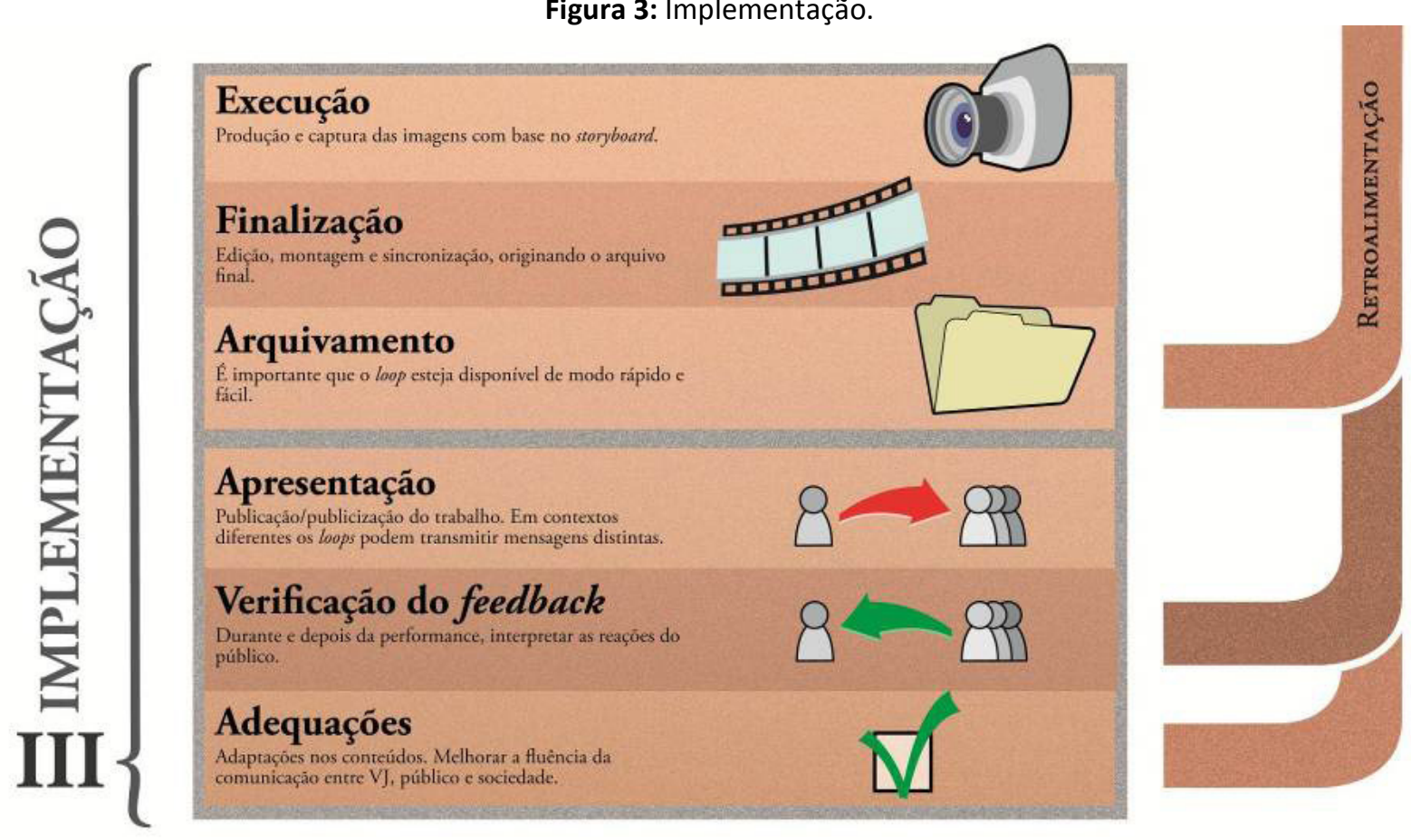

Figura 4: Efeito das sucessivas aplicações do modelo proposto. Conceituaçáo

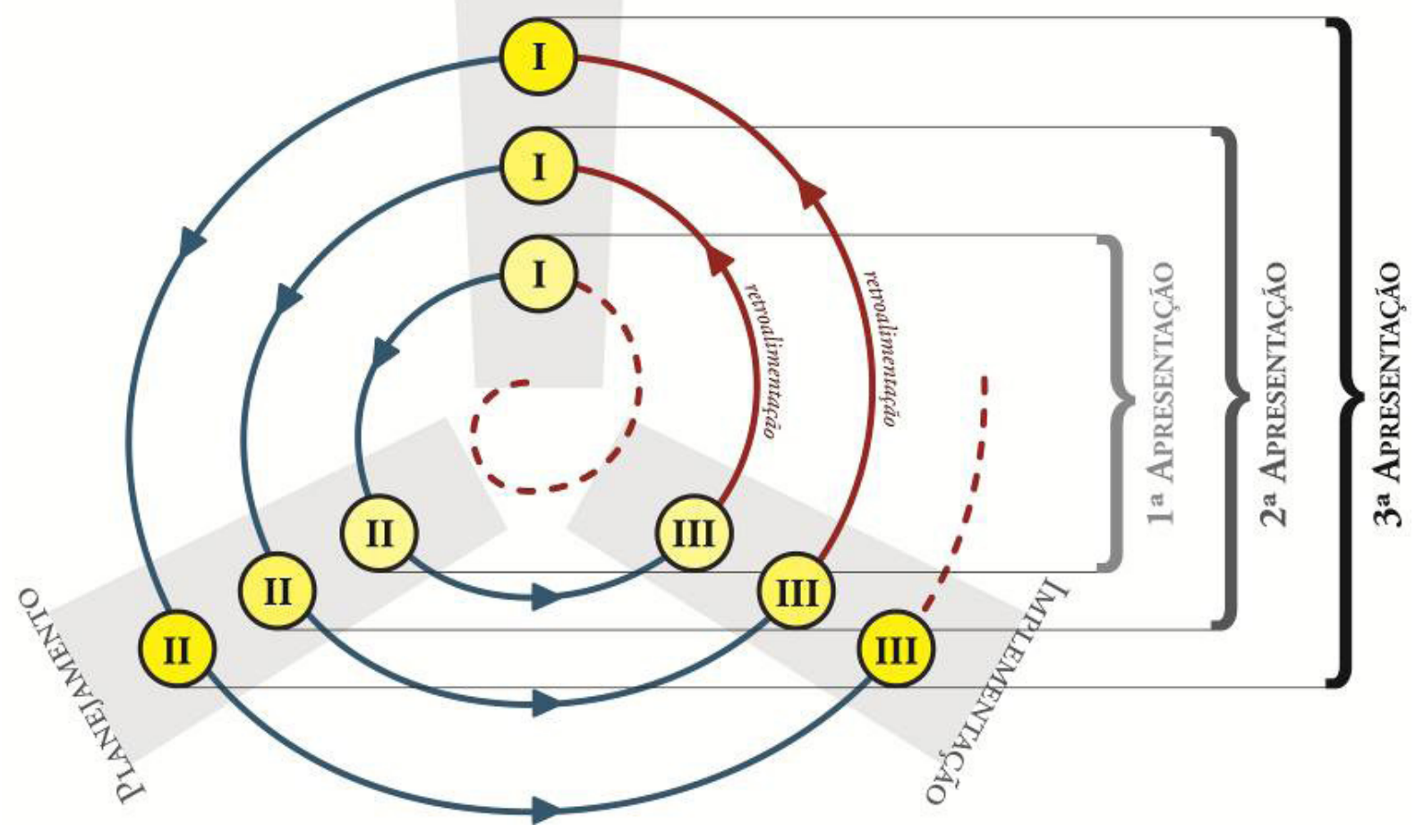




\section{Potencialidades e identidades para o VJ}

A atividade do Video Jockey está em constante mutação e reconfiguração. Por ser uma prática contemporânea, criativa, inovadora e relativamente recente, o VJing se renova continuamente, ajustando seu leque de funções socioculturais de acordo com os contextos espaço-temporal e antropológico. A cena do VJing está em contínua expansão. Produções e publicações de material e conteúdo são sempre bem vindas. A cultura do Video Jockeying se apropria de fundamentos de outras disciplinas congregando-os em um trecho limitado de espaço e tempo, o que evidencia suas capacidades sintéticas, objetivas. (LAZAR, 2007). Percebese o VJing, tanto em sua estrutura quanto em suas definições, como uma atividade volátil e maleável, com a possibilidade de assumir diversas formas e comunicar por meio de variados meios. Acredita-se que este princípio colaborativo e relativamente caótico seja indissociável do Video Jockeying, uma vez que, num ambiente múltiplo, pluridimensional, transdisciplinar e comunicacional, a maioria das práticas que se estagnassem estaria fadada à obsolescência.

No que se refere à produção de conteúdos, o conhecimento, assim como todo o proceder do VJ, opera prioritariamente nas dimensões estética (fruitiva, sensorial), antropológica (grupal, contextual, linguística) e tecnológica (midiática, processual). A forma como o indivíduo que conduz a performance seleciona, recupera e aplica o conteúdo de seus acervos estéticos, antropológicos e tecnológicos, independente do tema abordado, é fator determinante para a definição (consciente ou não) de seu discurso, estilo, estética, autoria e poética.

A experiência conduzida pelo VJ é construída em conjunto com os espectadores. A comunicação só se completa quando há uma cadeia deliberada de transmissão de signos por meio de um ou mais códigos comuns entre indivíduos. Conforme Pignatari (1970), os participantes do processo comunicacional assumem papeis, ora de estimulador, ora de interventor, conferindo dinamismo ao ciclo e tendendo ao equilíbrio entre as partes imersas no processo eminentemente lúdico e catártico.

\section{REFERÊNCIAS}

BORGES, Maria Lúcia. Como a música "ressoa" no design? E o design, na música? 2006. Disponível em: <http://goo.gl/Df4k0>. Acesso em: 3 abr. 2011.

CESTARI, Guilherme. Pesquisa, análise e conhecimentos para o Visual Jockey: fundamentos para a produção de conteúdo audiovisual editável. 2011. Monografia (Bacharel em Design Gráfico) Universidade Estadual de Londrina, Londrina.

ECO, Umberto. Obra aberta: forma e indeterminação nas poéticas contemporâneas. São Paulo: Perspectiva, 1997.

LAZAR, Ziv. VJ - A pseudo subculture. 2007. Disponível em: <http://goo.gl/jB1XC>. Acesso em: 13 jun 2011.

MACHADO, Arlindo. Arte e mídia. 1. ed. Rio de Janeiro: Jorge Zahar, 2007. v. 1. 84 p.

MORAN, Patricia. VJ em cena: espaços como partituras audiovisuais. Revista Contracampo, UFF, v. 01, p. 155-168, 2005.

p.63-77.

. Uma poética entre a transensorialidade e a correspondência. Revista Significação, USP, n.33,

MUNARI, Bruno. Artista e designer. Lisboa: Edições 70. 2004. 
CESTARI, Guilherme Henrique de Oliveira

PENTEADO, Rodolfo Araki. Arte generativa, live code e vjing. 2006. Trabalho de conclusão de curso (Especialização em Mídias Interativas) - Centro Universitário Senac, São Paulo.

PIGNATARI, Décio. Informação, linguagem e comunicação. São Paulo: Perspectiva. 1970.

SANTAELLA, Lucia. Matrizes da linguagem e pensamento: sonora, visual e verbal: aplicações na hipermídia. 3 ed. São Paulo: Iluminuras: FAPESP, 2005.

SANTAELLA, Lucia; NÖTH, Winfried. Imagem: cognição, semiótica, mídia. São Paulo: Iluminuras, 2008. 